\title{
NUEVAS CARACTERÍSTICAS APORTADAS POR EL ENTORNO VIRTUAL A LA COMUNICACIÓN
}

\section{NEW FEATURES PROVIDED BY THE VIRTUAL ENVIRONMENT TO COMMUNICATE}

\section{AUTORES}

Beatriz Peña Acuña

Profesor Doctor de la Universidad Católica de Murcia (UCAM). Murcia (España).

bpena@pdi.ucam.edu

\section{María Mónica Rubio Vega}

Bióloga por la Universidad de Navarra. Pamplona (España). Licenciada en Periodismo por la Universidad de Murcia. Murcia (España).

mrubiovega@yahoo.es

\section{Ana Pérez Caselles}

Licenciada en Periodismo por la Universidad de Murcia. Murcia (España). Profesora de Secundaria. Murcia (España).

anaisabel.perez2@educarm.es

\section{RESUMEN}

Las ideas descritas por Thompson respecto a la naturaleza de los cambios que Internet imprime a las sociedades y, más en concreto, al mundo de la comunicación, expuestas como novedades en el libro Los media y la modernidad, y que se incluyen en el capítulo titulado "Comunicación y contexto social", se han verificado en las sociedades actuales tal y como pronosticaba el autor. Allí donde los recursos económicos lo han permitido, la penetración de Internet -y las modificaciones que éste conlleva- ha sido universal y ha alcanzado una gran profundidad (véase en la gráfica más adelante que en Latino América alcanza el cuarto puesto por regiones 
mundiales, destacando la isla caribeña de Santa Lucía, en un quinto puesto por países).

A su vez, esta penetración se está produciendo de una forma tan natural que gran parte de la sociedad no es ahora consciente de los cambios que está experimentando y de los que es protagonista, razón por la cual consideramos que el artículo merece una revisión actual.

\section{PALABRAS CLAVE}

Comunicación - Sociedad - Internet - Nuevas tecnologías.

\section{ABSTRACT}

The ideas described by Thompson regarding the nature of the changes the Internet printing to society and, more specifically, to the world of communication, set out as novelties in the book The media and modernity, and included in the chapter entitled "Communication and social context", have occurred in modern societies as predicted by the author. Where financial resources have allowed, Internet penetration, and the changes that it entails, has been universal and has achieved a great depth, ((see chart below that in Latin America reached the fourth largest global regions, highlighting the Caribbean island of St. Lucia in a fifth country.))

In turn, this penetration is occurring in a manner so natural that much society is not now aware of the changes taking place and that is the star, which is why we believe that the article deserves a contemporary review.

\section{KEY WORDS}

Communication - Society - Internet - New technologies. 


\section{ÍNDICE}

1. Introducción

2. Ideas principales

2.1 Ideas relevantes

2.1.1 El tejido social y el poder.

2.1.2 El poder y la comunicación en las sociedades.

2.1.3 Las nuevas características de los recursos de la comunicación (medios de información y comunicación).

2.1.4 Características de la comunicación de masas.

2.1.5 El contexto, aspecto fundamental en el intercambio de formas simbólicas.

2.2 Ideas subordinadas

\subsubsection{Tipos de poder}

2.2.2 El soporte aporta características a las formas simbólicas

3. Crítica al artículo

4. Conclusiones

5. Bibliografía 


\section{Introducción}

Esta disertación pretende presentar las ideas más importantes del artículo "Comunicación y contexto social" que pertenece a la obra Los media y la modernidad de John B. Thompson, publicado en 1995 en EE.UU. y en 1998 en España, así como ofrecer una visión crítica y un comentario académico sobre la cuestión.

Comenzamos diciendo que

"se entiende 'red' como una trama de nódulos autónomos y relacionados, tal y como es la propia naturaleza humana y su vertiente relacional: individual y social. El ciberespacio ha sido acogido por los países desarrollados que han invertido en investigación en nuevas tecnologías y en proyectos educativos desde hace décadas" (Peña Acuña, B. 2009, pág. 1).

Hemos elegido comentar y abordar una revisión actualizada de este artículo, tan impactante en el momento de su publicación, porque nos parece destacable el modo en el que revela la forma en que Internet ha penetrado y modificado la manera de comunicarse de la sociedad, e incluso, más allá, el modo en que esta sociedad entiende su entorno. El paso del tiempo permite, además, observar la adecuación o inadecuación de las entonces ideas novedosas de Thompson.

Este artículo está compuesto de tres partes principales. En la primera desarrollamos las ideas que nos parecen más importantes. En la segunda, hacemos una crítica al artículo desde el punto de vista de la lógica y la exposición de las ideas por parte del autor. $\mathrm{Y}$ en la tercera parte, nos permitimos sacar conclusiones de todo lo expuesto en este interesante artículo referenciado. 


\section{Ideas principales.}

\subsection{Ideas relevantes.}

\subsubsection{El tejido social y el poder.}

Thompson afirma que:

"los fenómenos sociales pueden ser vistos como acciones llevadas a término en tejidos sociales estructurados", donde "los individuos ocupan posiciones diferentes en el interior de estos campos, dependiendo de los diferentes tipos y cantidad de recursos disponibles para ellos" (Thompson, 1998, pág. 28).

En esta línea, el académico señala que, en algunos casos, estas posiciones adquieren una cierta estabilidad a través de la institucionalización, "convirtiéndose en parte de un paquete de reglas, recursos y relaciones sociales relativamente estables" (Thompson, 1998, pág. 28), de modo que "la posición que ocupa un individuo dentro de un campo o institución está íntimamente relacionada con el poder que él o ella poseen" (Thompson, 1998, pág. 29), sostiene finalmente, encarando el tema que más le preocupa: el poder.

El poder es "la capacidad para operar de acuerdo a la conquista de los designios e intereses de cada uno, la capacidad de intervenir en el curso de los acontecimientos y de afectar los resultados" (Thompson, 1998, pág. 29), y "mediante la acumulación de recursos de varios tipos, los individuos pueden aumentar su poder" (Thompson, 1998, pág. 29). Con frecuencia, dice, estos recursos "también se acumulan dentro de una estructura institucional, que constituyen un importante escenario para el ejercicio del poder" (Thompson, 1998, pág. 29). Las instituciones, aclara, dan forma concluyente a campos de interacción preexistentes y al mismo tiempo crean nuevas 
posiciones en el interior de estos tejidos, así como nuevos caminos para organizar la vida de las personas que los ocupan.

Así, indica que "los Estados se han transformado en ejes particularmente importantes de congregación de poder en el mundo moderno". Al mismo tiempo, describe cómo

\begin{abstract}
"los sujetos generalmente ejercen el poder en muchos entornos que tienen poco o nada que ver con el Estado. De esta manera, ambos opinan y permiten establecer relaciones relativamente seguras 0 redes de poder $y$ dominio entre personas, $y$ entre grupos de individuos, que dominan diferentes posiciones en campos de interacción".
\end{abstract}

El poder es un fenómeno social penetrante característico de los diferentes tipos de acciones y encuentros, desde las acciones políticas visibles de los representantes del Estado hasta el mundano encuentro de personas en las calles (Thompson, 1998, p. 29) donde "el poder público político y manifiesto constituye sólo una forma de poder un tanto especializadd' (Thompson, 1998, pág. 29).

\title{
2.1.2. El poder y la comunicación en las sociedades
}

La comunicación, apunta más adelante el autor, "es un tipo diferenciado de actividad social que implica la producción, transmisión y recepción de formas simbólicas, y que compromete la materialización de varios recursos" (Thompson, 1998, pág. 36).

Dentro de la clasificación de los distintos tipos de poder, Thompson se detiene en el 'poder simbólico': "la actividad simbólica es una característica fundamental de la vida social' (Thompson, 1998, pág. 33), y esta acción social de producir e intercambiar formas simbólicas puede "interferir en el decurso de los acontecimientos" (Thompson, 1998, pág. 34). 'Poder simbólico', dice, es "la capacidad de intervenir en 


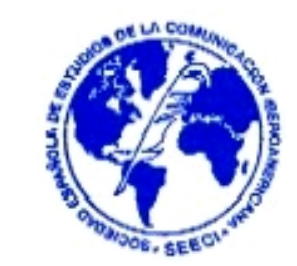

el transcurso de los acontecimientos, para influir en las acciones de los otros y crear acontecimientos reales, a través de los medios de producción y transmisión de la formas simbólicas" (Thompson, 1998, pág. 34). Así, incide en que las acciones simbólicas pueden dar lugar a un incremento de las reacciones, a actuar de determinadas maneras y dar preferencia a un tipo de acción antes que a otro para creer o para dejar de creer.

"La actividad simbólica es una característica penetrante que se expande por doquier de la vida social' (Thompson, 1998, pág. 34), afirma el autor, quien detalla que los individuos emplean, para esta transmisión simbólica, varios tipos de recursos, que Thompson designa como "medios de información y comunicación" (Thompson, 1998, pág. 34). Además, añade que hay "un conjunto de instituciones que han asumido el papel histórico particularmente importante en la acumulación de los medios de información y comunicación" y que son las instituciones religiosas, educativas y mediáticas (Thompson, 1998, pág. 34), y que han dado forma "a las maneras en que la información y los contenidos simbólicos son producidos y puestos en circulación en el mundo social' (Thompson, 1998, pág. 35).

El análisis de la comunicación, defiende a su vez el autor, debe basarse en un estudio de la acción y una elucidación de su perfil contextualizado.

La estructura actual del poder, sostiene Thompson, lleva asociadas unas transformaciones institucionales (Thompson, 1998, pág. 36), que analiza en los siguientes epígrafes.

\subsubsection{Las nuevas características de los recursos de la} comunicación (medios de información y comunicación)

Dentro de los cambios que han experimentado los medios de información y comunicación (que, por cierto, tienen un sentido amplio para el autor, en el que 


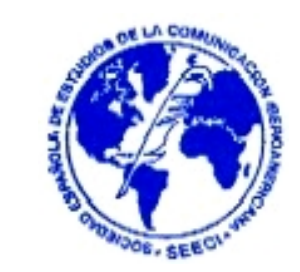

incluye habilidades, conocimientos y demás recursos), el autor se detiene en la alteración de las condiciones comunicativas espacio-temporales (Thompson, 1998, pág. 41): "el uso de los de los medios técnicos también altera las condiciones espacio-temporales bajo los cuales los humanos ejercen el poder" (Thompson, 1998, pág. 42). Estos medios son ahora capaces de "intervenir e influir en el curso de los acontecimientos que suceden en lugares espacial y temporalmente remotos" (Thompson, 1998, pág. 42).

Más adelante, dedica un epígrafe a profundizar en este aspecto, donde añade que con las telecomunicaciones, "la distancia espacial dejó de requerir distancia temporal" (Thompson, 1998, pág. 53). El retraso en el tiempo quedó eliminado y el ámbito espacial se intensificó de manera espectacular, apunta.

La separación del espacio y del tiempo preparó el camino para otra transformación: "el descubrimiento de la 'simultaneidad desespaciada"' (Thompson, 1998, pág.53). La simultaneidad ya no presupone estar en un mismo lugar.

Así, "la creciente disponibilidad de formas simbólicas mediáticas ha alterado gradualmente la manera en la que la mayoría de personas adquieren un sentido del pasado y del mundo más allá de su ubicación inmediata", revela el estudioso (Thompson, 1998, pág. 55), y ha dado lugar a los fenómenos que llama "historicidad mediática" (Thompson, 1998, pág. 55), al conocer el pasado a través de los media, y "experiencia mediática" (Thompson, 1998, pág. 56), al conocer a otros que están alejados en el espacio, igualmente, a través de los media. Todo ello afecta, dice, "al sentimiento de pertenecer un grupo o comunidad' (Thompson, 1998, pág. 56), que se verá más alterado en la medida en que más se acceda al conocimiento del pasado a través de las formas simbólicas mediáticas, porque dejamos de compartir "unas experiencias comunes a través del tiempo y el espacio, un origen común y un destino común: sentimos que pertenecemos a grupos y comunidades que se han constituido a través de los media" (Thompson, 1998, pág. 57). Es la "sociabilidad mediática". 
Los media, indica en este sentido, han alterado también el sentido de la experiencia mediática, pues se experimentan acontecimientos y se aprenden de un mundo que se extiende más allá de la esfera de lo cotidiano. Asimismo, los medios contribuyen a la nueva percepción de la distancia por parte de los humanos. Incide en este pensamiento al añadir que ahora se ofrece a los sujetos nuevas maneras de organizar y fiscalizar el espacio y el tiempo, así como nuevas maneras de recurrir al espacio y al tiempo para lograr sus propósitos. "Podría incluso tener un profundo impacto en la forma en que los individuos experimentan las dimensiones espaciales y temporales de la vida social', sostiene.

\subsubsection{Características de la comunicación de masas}

A la comunicación de masas (término que, por otra parte, no gusta mucho a Thompson) dedica el autor todo un epígrafe, en el que señala que la característica más destacada de esta comunicación "es que los productos estén disponibles, en principio, a una pluralidad de destinatarios" (Thompson, 1998, pág. 44). Considera que se debe "abandonar la suposición de que los destinatarios de los productos mediáticos son observadores pasivos" (Thompson, 1998, pág. 45) ya que los productos mediáticos son aceptados hoy por los individuos a través de actividades receptoras y formas complejas, en un proceso "de transmisión estructurada" (Thompson, 1998, pág. 45). Idea que repite más adelante (Thompson, 1998, pág. 61). Así, indica que la recepción de la información es una actividad, una práctica, que es, además, situacional y que debe entenderse como una actividad rutinaria (Thompson, 1998, pág. 63).

Esta recepción activa, situacional y rutinaria (Thompson, 1998, pág. 62-63) es un logro habilidoso y un proceso hermenéutico (Thompson, 1998, pág. 64), describe Thompson, quien añade que al recibir y apropiarse de los mensajes mediáticos, los sujetos a su vez se implican en un proceso de autoformación y autocomprensión. 
Los primeros procesos de socialización en la familia y la escuela son, en muchos sentidos, decisivos para el desarrollo posterior del individuo y su autorrepresentación. Sin embargo, advierte el estudioso, los individuos viven actualmente en un mundo cada vez más impregnado por los productos de las industrias mediáticas, ha surgido un nuevo escenario a partir del proceso de autoactualización.

Refiere también que la comunicación de masas ha implicado por lo general la explotación comercial de las innovaciones técnicas (Thompson, 1998, pág. 47), llevada a cabo por las mismas instituciones que "continúan dando forma a las maneras en que los media operan hoy en día" (Thompson, 1998, pág. 47). El académico relaciona ese hecho con la segunda característica: "la producción para el consumo de formas simbólicas (commodities)" (Thompson, 1998, pág. 47), aunque, aclara, la producción de bienes para el consumo no es exclusiva de la comunicación de masas (Thompson, 1998, pág. 49).

La tercera característica es que "instituye una ruptura estructurada entre la producción de formas simbólicas y su recepción" (Thompson, 1998, pág. 49), ya que los bienes simbólicos se producen en un contexto y se reciben en otros distintos, lejanos y diversos.

La extensión de la disponibilidad de las formas simbólicas en el espacio y en el tiempo es la cuarta característica (Thompson, 1998, pág. 51), muy ligada a la anterior. Así, aquéllas pueden ser recibidas por individuos muy alejados en el espacio y/o en el tiempo de quienes las han producido.

Finalmente, para Thompson, la quinta característica es "la circulación pública de las formas simbólicas" (Thompson, 1998, pág. 51), con múltiples copias y multiplicidad de receptores. 


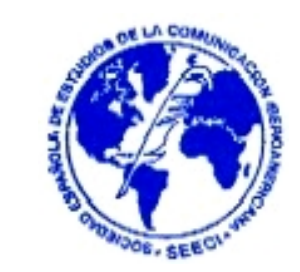

\subsubsection{El contexto, aspecto fundamental en el intercambio de}

\section{formas simbólicas}

Thompson insiste repetidas veces en "la importancia de pensar sobre los medios de comunicación en relación a los contextos sociales prácticos en los que los individuos producen y reciben formas simbólicas mediáticas" (Thompson, 1998, pág. 60). Es una idea que ya avanzaba al principio del capítulo: "El análisis de la comunicación debe basarse [...] en un análisis de la acción y una explicación de su carácter socialmente contextualizado" (Thompson, 1998, pág. 27). Se lamenta así de que estos fenómenos "son generalmente analizados sin considerar de manera sistemática y detallada las condiciones bajo las que fueron producidos y recibidos", "Ios propósitos y recursos de aquellos que los producen" y "las maneras en que son utilizados y comprendidos por aquellos que los reciben" (Thompson, 1998, pág. 60). Además, matiza que para estos estudios, hay que realizar una aproximación "sensible a los aspectos rutinarios y prácticos de la actividad receptora" (Thompson, 1998, pág. 61). Lo que defiende, en definitiva, el académico es que "un mismo mensaje pueda comprenderse de manera distinta en contextos distintos" (Thompson, 1998, pág. 62).

Tal es la importancia que Thompson da a esta idea a lo largo del texto que aún la repite una vez más: "... las maneras en que se comprende un producto mediático puede variar de un individuo a otro (o grupo de individuos), y de un contexto sociohistórico a otro" (Thompson, 1998, pág. 65-55).

\subsection{Ideas subordinadas}

\subsubsection{Tipos de poder}

Para el autor, existen cuatro tipos principales de poder: económico, político, coercitivo y simbólico (Thompson, 1998, pág. 30). 


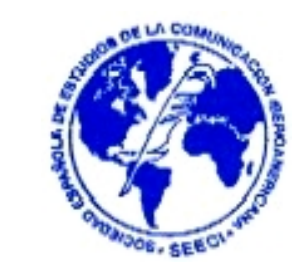

El poder económico (Thompson, 1998, pág. 31), dice, proviene de la actividad humana productiva, la que se ocupa de proveer los medios de subsistencia a través de la extracción de las materias primas y su transformación en bienes que pueden gastarse 0 intercambiarse en un mercado. Estos recursos pueden ser acumulados por individuos y organizaciones con el propósito de difundir su actividad productiva, y, al mismo tiempo, "sirven para aumentar su poder económico" (Thompson, 1998, pág. 31). Con el desarrollo de las sociedades modernas, las instituciones de poder económico han proliferado la progresión y envergadura de sus movimientos y han adquirido un perfil más variado.

Thompson entiende que el poder político (Thompson, 1998, pág. 32) coordina a los sujetos y regula los patrones de su interacción. Se puede identificar un grupo de instituciones implicadas "básicamente con la conexión y la regulación" (Thompson, 1998, pág. 32), y que tratan de llevar a cabo estas actividades de manera relativamente centralizada dentro de un territorio más o menos circunscrito.

El poder coercitivo (Thompson, 1998, pág. 33) supone el uso o amenaza de utilizar de la fuerza física para someter o vencer al oponente. Puede ser aumentado mediante la utilización de armas y equipo, a través del entrenamiento y de la táctica, utilizando la inteligencia y la planificación, etc. La forma más característica de este poder, opina, es el poder militar, y, así, destaca que la historia de los Estados descubre cómo han encaminado gran parte de sus acciones a acumular poder militar, hacia la extracción de recursos materiales necesarios para sostener las fuerzas armadas.

Por último, el poder simbólico o cultural (Thompson, 1998, pág. 33) procede de la actividad productiva, transmisora y receptora de formas simbólicas significativas. " $L a$ actividad simbólica es una característica fundamental de la vida social' (Thompson, 1998, pág. 33), afirma. Los individuos "están constantemente dedicados a la actividad de expresarse de forma simbólica y de interpretar las expresiones de los 
otros" (Thompson, 1998, pág. 33), para lo que emplean varios tipos de recursos, que el autor designa como "medios de información y comunicación" (Thompson, 1998, pág. 34), y que incluyen medios técnicos, habilidades, competencias y conocimientos, así como el reconocimiento a determinados productores e instituciones.

\subsubsection{El soporte aporta características a las formas simbólicas}

La comunicación implica la producción, transmisión y recepción de formas simbólicas, lo que conlleva siempre un soporte técnico de algún tipo (Thompson, 1998, pág. 36), que se caracteriza por aspectos como la fijación (Thompson, 1998, pág. 37), la reproducción (Thompson, 1998, pág. 38) y la separación espacio-temporal (Thompson, 1998, pág. 40). La naturaleza de los soportes técnicos difiere enormemente de un tipo de producción simbólica a otro y sus propiedades facilitan y circunscriben la producción y su intercambio (Thompson, 1998, pág. 36). Estos contenidos, con sus características derivadas del soporte utilizado, pueden utilizarse posteriormente como un recurso para el ejercicio de diferentes formas de poder (Thompson, 1998, pág. 37), mientras que ya al principio del capítulo, Thompson había avanzado que "las formas simbólicas se han convertido en bienes de consumo" (Thompson, 1998, pág. 25 y 38).

\section{Crítica al artículo}

En cuanto a la estructura, consideramos que el texto que presenta Thompson está muy bien ordenado, comenzando por el modo en que resume el capítulo en su introducción. Después, avanza despacio, aunque denso, separando las ideas por epígrafes. En ocasiones, los propios epígrafes tienen un párrafo introductorio que presenta el tema de manera clara, lo que ayuda a fijar las ideas. Además, el artículo es de fácil lectura, aunque a veces se detiene en explicaciones colaterales quizá un tanto largas. 
El discurso está bien hilvanado y presenta coherencia de las hipótesis que defiende. Las ideas que expone con novedad en su momento, año 1995 en EE.UU. y 1998 en España, poseen la solidez necesaria. Al releerlas años después, se constata la veracidad de sus hipótesis, por lo que hoy resultan ideas muy obvias; pero nos gusta destacar al respecto que esta lectura ayuda a hacer patente que el usuario actual de las tecnologías de la Red no siempre percibe cómo éstas están cambiando su manera de entender el mundo que le rodea, cuestión que, de hecho, constituye una de las ideas relevantes que aporta Thompson.

Así, trece años después de su publicación en español, ésta es precisamente la condición que hace que este artículo resulte especialmente interesante. Las nuevas tecnologías han penetrado con tal naturalidad, extensión y profundidad en la sociedad, que ésta, y sobre todo su fracción más joven, que carece de la comparación histórica personal, ha dejado de ser consciente de los cambios que ha introducido en sus relaciones, en la cuestión del poder, en el intercambio simbólico y en distintos aspectos de la socialización. Ello propicia una lectura renovada de este trabajo de Thompson.

Para contemplar la penetración de Internet en las sociedades, aportamos los datos al respecto recogidos en www.exitoexportador.com/stats.htm, extraídos el 5 de marzo de 2009: 


\section{ESTADÍSTICAS MUNDIALES DEL INTERNET Y DE LA POBLACIÓN}

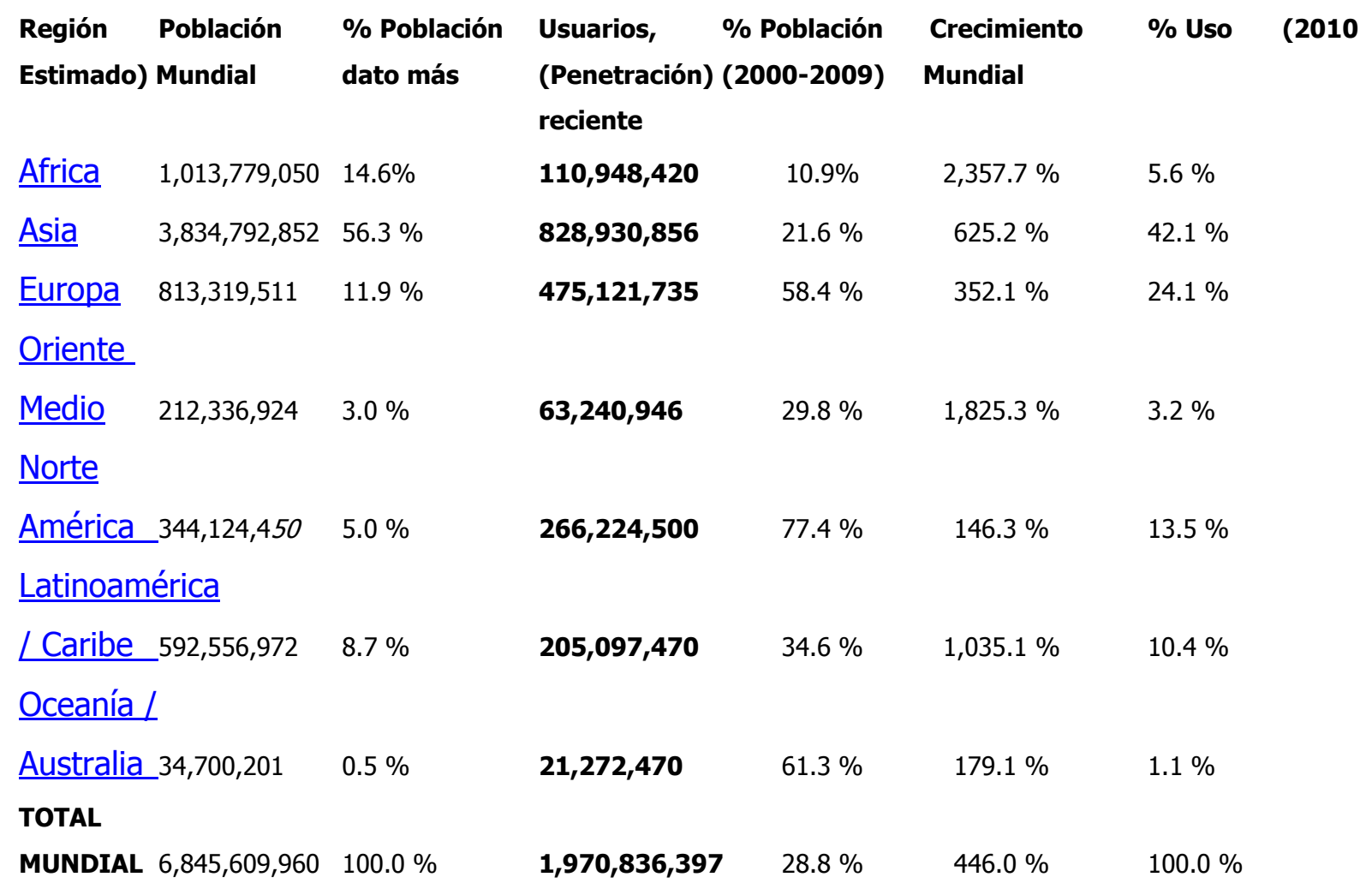

NOTAS: (1) Las Estadísticas de Usuarios Mundiales del Internet fueron actualizadas a Agosto 31, 2009. (3) Los datos de población se basan en cifras para 2009 del US Census Bureau. (4) Los datos de usuarios provienen de información publicada por Nielsen, ITU y de Internet World Stats. (6) Estas estadísticas son propiedad intelectual de Miniwatts Marketing Group, se pueden citar, siempre manifestando el debido crédito y estableciendo un enlace activo a www.exitoexportador.com. 
Peña Acuña, Beatriz; Rubio Vega, María Mónica; Pérez Caselles, Ana (2009): Nuevas características aportadas por el entorno virtual a la comunicación. No 19. Julio. Año XIII. Páginas: 1- 22

ISSN: 1576-3420 DOI: http://dx.doi.org/10.15198/seeci.2009.19.1-22

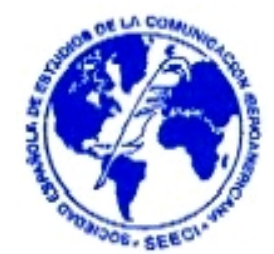

El mismo enlace añade los siguientes gráficos:
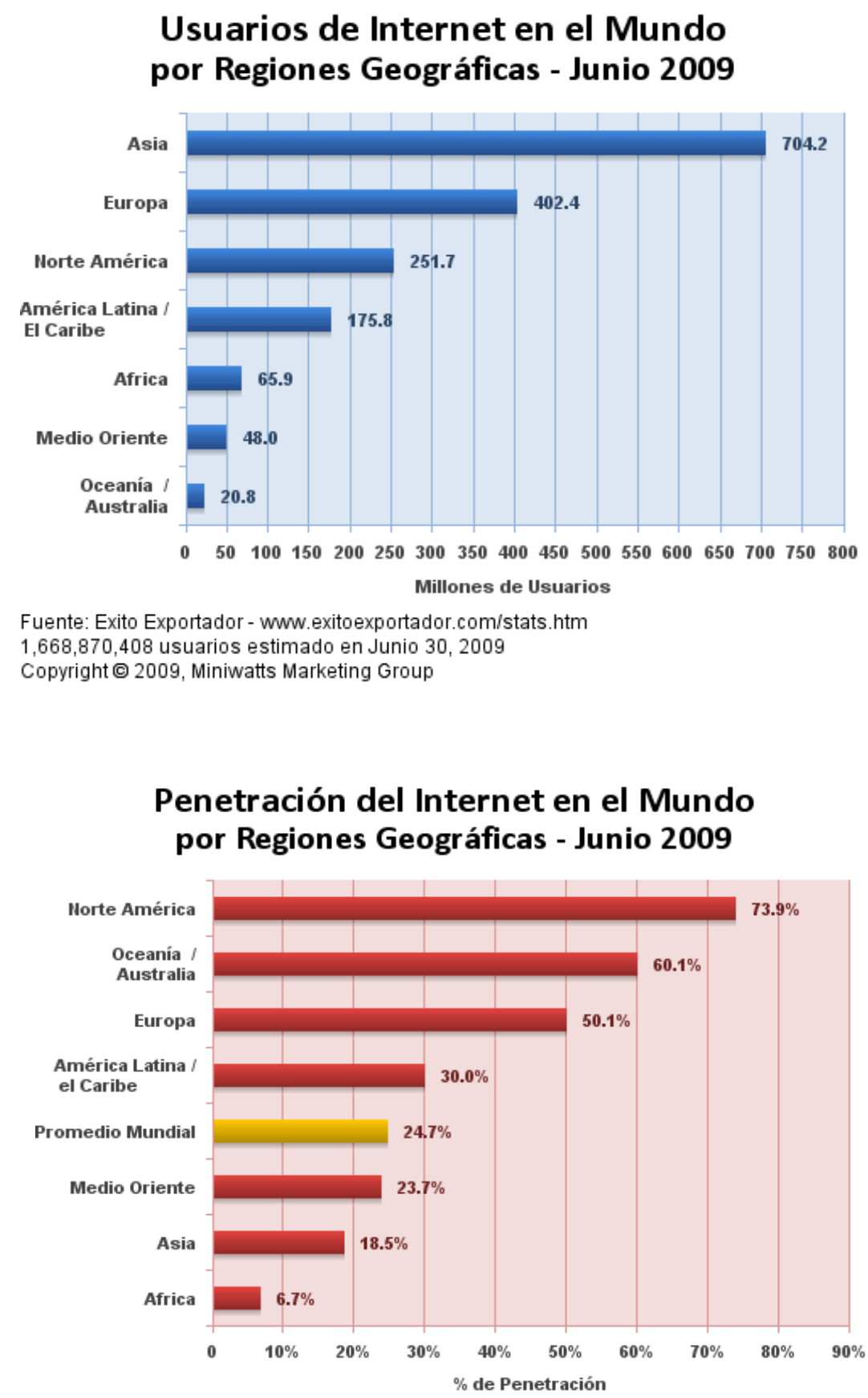

Fuente: Exito Exportador - wnw exitoexportador com/stats. htm

El porcentaje de Penetración del Internet se basa en un estimativo de 6,767,805,208

para la población mundial y de 1,668,870,408 usuarios de Internet en Junio 30,2009 Copyright $\odot 2009$, Miniwatts Marketing Group 
A su vez, indica también la tasa de penetración por países:

\section{LOS 10 PAÍSES DEL INTERNET \\ CON LA MÁS ALTA TASA DE PENETRACIÓN}

(PORCENTAJE DE LA POBLACIÓN QUE UTILIZA EL INTERNET)

\section{\# PAÍS O REGIÓN}

Población

Usuarios,

Penetración

Fuente del

(2010 Estimado) Dato Más Reciente (\% población) Dato Más Reciente

$\begin{array}{llllll}\mathbf{1} & \text { Islandia } & 308,910 & 301,600 & \mathbf{9 7 . 6} \% & \text { ITU - Jun/09 } \\ \mathbf{2} & \text { Noruega } & 4,676,305 & 4,431,100 & \mathbf{9 4 . 8} \% & \text { ITU - Jun/09 } \\ \mathbf{3} & \text { Suecia } & 9,074,055 & 8,397,900 & \mathbf{9 2 . 5} \% & \text { ITU - Jun/09 } \\ \mathbf{4} & \text { Groenlandia } & 57,637 & 52,000 & \mathbf{9 0 . 2} \% & \text { ITU - Mar/09 } \\ \mathbf{5} & \text { Santa Lucía } & 160,922 & 142,900 & \mathbf{8 8 . 8} \% & \text { ITU - Jun/09 }\end{array}$

NOTAS: (1) Las Estadísticas de Penetración del Internet fueron actualizadas para Agosto 31, 2009. (3) Los datos de población se basan en las cifras para 2009 del US Census Bureau. (4) Los datos de usuarios provienen de información publicada por Nielsen, de ITU, de Internet World Stats y otras fuentes confiables. (6) Esta información se puede citar, siempre y cuando se otorgue el debido crédito y se establezca un enlace activo a www.exitoexportador.com.

En lo que respecta al contenido, apuntamos que los autores de este trabajo estamos de acuerdo en las principales hipótesis que presenta como novedosas, sobre todo con la recepción activa y participativa que se ha comprobado en muchos estudios empíricos sobre recepción.

Nos gusta, en concreto, la idea del consumidor de los medios de masas como un agente activo. Sugerimos al respecto que la llegada de nuevos canales de televisión y radio y, por supuesto, Internet y los podcasts, han contribuido al despertar de la audiencia media: ahora que hay donde elegir, hay que valorar lo que es bueno/malo, lo que conlleva aplicar un criterio de usuario: hay que analizar si el espectador se pierde algo que le gusta por no cambiar de canal... Antes, en el caso de España, con dos canales hasta los años 80 -momento en que, en algunas comunidades, aparecen las televisiones autonómicas-, no merecía la pena molestarse, es decir, ser activo; y 


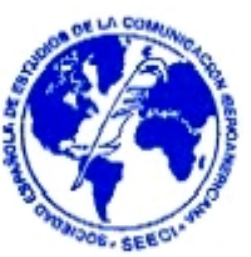

la situación se mantuvo similar hasta principios de los 90 , cuando se introducen casi media docena de cadenas generalistas. El espectador que ha pasado por estas distintas épocas es el que más consciente es de este cambio.

Asimismo, a modo de comentario que nos sitúa en el panorama actual, para ilustrar el alcance de la visión de Thompson en este artículo sobre la incidencia de la Red en las relaciones sociales, señalamos que el estudio de la Asociación de Investigación de los Medios de Comunicación (AIMC) aporta los siguientes resultados acerca del establecimiento de nuevas relaciones de los españoles a través de Internet en 2009: un $14^{\prime} 5$ establece y mantiene relaciones solamente en la red, un 22 ' 3 establece relación tanto dentro como fuera de la red y un $61^{\prime} 4$ no establecieron relaciones sociales en la red (AIMC 2009, pág. 117).

Consideramos discreto el primer dato, referido al mantenimiento de relaciones solamente en la red, mientras que el segundo nos parece más alentador, pues de este modo Internet se convierte en una herramienta útil para conocer gente nueva y establecer lazos reales. El tercer dato nos revela que en España todavía el uso de las redes sociales no está tan desarrollado como en EE.UU.

Aventuramos, en este sentido, que la capacidad socializadora del uso de los medios que facilita Internet, como los chats, los foros $y$, en concreto, las redes sociales, cuando se comparte una noticia o una opinión política o moral, implica una acción universalizadora y multiplicadora de los contenidos que puede crear estereotipos, e incluso una homogeneización de un público de por sí heterogéneo. Se trata de un proceso que por otro medio sería más complicado, que, sin embargo, está unido por una misma vivencia y reacción ante un evento social o cultural.

Como afirma Castells, "Internet permite una comunicación horizontal de ciudadano a ciudadano" donde puede crear su propio sistema de comunicación; puede decir lo que quiera, pues se trata de una capacidad de comunicación masiva no mediatizada 
por los Medios de Comunicación (Castells, 2000, pág. 17). Pensamos que este factor introduce una vivencia nueva en el ciudadano y, hasta un punto, puede dotarle de una nueva mentalidad política; así, el internauta puede influir libremente, sin censuras, con su opinión, en otros ciudadanos con los que se puede agrupar y formar un grupo representativo que tenga que ser tenido en cuenta por las autoridades.

\section{Conclusiones}

El análisis nos ha aportado una reflexión sobre las distintas formas de poder. Lo que nos ha parecido más sugerente es cómo las condiciones espacio-temporales de la experiencia mediática afectan a la concepción y la percepción del individuo, que se muestra en un proceso de autoactualización dinámico.

Como decimos arriba, ciertas ideas relevantes que aborda Thompson en 1998 son conocidas a estas alturas del siglo XXI. Los cambios que traen las nuevas tecnologías, por ejemplo, los hemos experimentado los usuarios sin grandes aspavientos: la velocidad de transmisión del mensaje, la ausencia de distancia, la respuesta rápida...; y también la manera en que todo se magnifica, para lo bueno y para lo malo: si al usuario le ocurre algo positivo, la noticia es conocida enseguida todo el mundo, y eso es bueno; si es algo que quisiera ocultar, también lo sabe enseguida todo el mundo, y eso es malo; Internet no entiende de cualidad, sino de acciones.

La cuestión significativa es que, si bien estos cambios son ciertos y constatables, la pérdida de su noticiabilidad, de la originalidad que conllevaban en el momento de su llegada, la pérdida de su impacto, por así decir, ha hecho que la sociedad, los usuarios de este entorno virtual, hayan dejado de ser conscientes de estos cambios, de los que son los verdaderos protagonistas. Consideramos, por ello, necesario retomar estas cuestiones y ponerlas de nuevo de actualidad, para determinar hacia 
dónde se dirige la sociedad, vehiculada por las posibilidades de comunicación en la Red.

Así, cabe destacar la interacción entre los medios y la estima creciente que están adquiriendo las redes sociales con respecto a la televisión, la radio y la prensa escrita, pues de alguna manera recogen el pulso de la opinión pública en tiempo real. Es, de nuevo, una expresión de la característica de acercamiento en el espacio y en el tiempo, con potencial de llegar al máximo de la ciudadanía.

Aparte de las ideas relevantes, estos textos encierran otros matices que despiertan nuestra curiosidad como lectores. Entre ellos, están los siguientes:

a) "La disponibilidad de los productos de la comunicación de masas tiene importantes implicaciones sobre los modos en que reflexionamos acerca de la distinción entre el dominio público y el privado" (Thompson, pág. 52).

Ocurre que lo privado, ahora, se hace más accesible al público.

b) La manera de experimentar el paso del tiempo, dice el autor:

"podría estar cambiando en la actualidad. En la medida en que se acelera el ritmo de vida, el futuro deja de extenderse ante nosotros como una tierra prometida. El horizonte continuamente cambiante de expectativas comienza a saturarse. [...] Cada vez resulta más y más difícil sostener una concepción lineal de la historia como progreso. La idea de progreso es una manera de colonizar el futuro, una manera de subsumir el futuro en nuestros planes presentes y nuestras expectativas. Sin embargo, en la medida en que los límites de esta estrategia cada día se hagan más evidentes, en la medida en que el 
futuro confunda repetidamente nuestros planes y expectativas, la idea de progreso empezará a perder su arraigo entre nosotros" (Thompson, 1998, pág. 59).

Estamos totalmente de acuerdo, y es de las afirmaciones que más nos ha hecho pensar en este texto.

c) "En relación con sus orígenes y sus principales beneficiarios, el desarrollo de las leyes del copyright tuvo menos que ver con la protección de los derechos de autor que con la protección de los intereses de los impresores y los libreros" (Thompson, 1998, pág. 39).

Un tema de total actualidad.

\section{Bibliografía}

ASOCIACIÓN PARA LA INVESTIGACIÓN DE LOS MEDIOS DE COMUNICACIÓN (AIMC), (2009): "Navegantes en la Red". Disponible en: www.aimc.es (Consultado el 12 de diciembre de 2009)

CASTELLS, Manuel (2000): "Internet y la sociedad red. Conferencia de presentación del Programa de Doctorado sobre la Sociedad de la información y el Conocimiento". Universitat Oberta de Catalunya.

Disponible en: http://tecnologiaedu.us.es/bibliovir/pdf/106.pdf (Consultado el $11 / 12 / 2009)$

CELAYA, Javier y HERRERA, Pau, (2007): Comunicación empresarial 2.0. La función de las nuevas tecnologías sociales en la estrategia de comunicación empresarial. Grupo MBO. Barcelona. 
CELAYA, Javier (2008): La empresa en la web 2.0, (3a edición). Gestión 2000. Barcelona.

KEMPE, David y otros (2003): "Maximazing the spread of influence through social network". Disponible en: www.cs.cornell.edu/home/kleinber/kdd03-inf.pdf (Consultado el 12/12/2009)

LUCAS MARÍN, Antonio, y otros (1999): Sociología de la comunicación, Trotta, Madrid.

MARTÍN ALGARRA, Manuel (2003): Teoría de la comunicación: una propuesta. Tecnos. Madrid.

PEÑA ACUÑA, B (2009): "Entender el origen y la naturaleza de Internet" en Revista de Comunicación Vivat Academia.

Disponible en: www.ucm.es/info/vivataca/numeros/n110/ensayos.htm\#entender (Consultado el 11/12/2009)

RAMÓN-CORTES, Ferrán (2008): La isla de los cinco faros, las cinco claves de la comunicación. RBA. Barcelona.

RODRIGO ALSINA, M. (1995): Los Modelos De La Comunicación (2a ed.). Tecnos. Madrid.

RODRIGO ALSINA, M., (2001): Teorías de la comunicación: ámbitos, métodos y perspectivas. Bellaterra, Servei de Publicacions de la Universitat Autónoma de Barcelona. Barcelona.

THOMPSON, JOHN B. (1998): Los media y la modernidad. Una teoría de los medios de comunicación. Ediciones Paidós Ibérica, S.A.. Barcelona. 